\section{Midazolam and awareness with recall during total intravenous anaesthesia}

Donald R. Miller MD, Philip G. Blew MD, Raymond J. Martineau MD, * Kathryn A. Hull RN
Purpose: A double-blind study was undertaken to evaluate the influence of graded doses of midazolam on propofol infusion requirements, recovery characteristics and the quality of recovery, associated with propofol/alfentanil/ $\mathrm{O}_{2}$ total intravenous anaesthesia (TIVA).

Methods: Ninety ASA Class I and II subjects scheduled for arthroscopic knee surgery were randomly allocated to receive either placebo (Group PLAC), or midazolam doses of 15, 30 or $45 \mu \mathrm{g} \cdot \mathrm{kg}^{-1}$ (Groups $\mathrm{M}-15, \mathrm{M}-30$ and M-45, respectively). Anaesthesia was induced and maintained with propofol (infused initially at $100 \mathrm{\mu g} \cdot \mathrm{kg}^{-1} \cdot \mathrm{min}^{-1}$, and adjusted thereafter according to anaesthetic depth) and alfentanil (loading dose of $20 \mu \mathrm{g} \cdot \mathrm{kg}^{-1}$, followed by infusion at $0.5 \mu \mathrm{g} \cdot \mathrm{kg}^{-1}$. $\left.\mathrm{min}^{-1}\right)$. Postoperatively, times to awakening, recovery, and discharge were evaluated, in addition to psychometric evaluations using the Trieger Dot Test (TDT).

Results: The study was discontinued prematurely, as six patients unexpectedly experienced intraoperative awareness with recall $(4 / 21=19.1 \%$ of patients with PLAC vs $2 / 69=$ $2.9 \%$ of patients in the midazolam groups, $P<0.04$ ). Induction requirements of propofol were found to be lower in

\section{Key words}

ANAESTHETICS, INTRAVENOUS: midazolam, propofol, alfentanil;

ANAESTHETIC TECHNIQUES: total intravenous anaesthesia; COMPLICATIONS: awareness with recall;

INTERACTIONS (DRUG): midazolam, propofol, alfentanil.

From the Department of Anaesthesia, Ottawa General

Hospital, and the University of Ottawa, Ottawa, Ontario.

Address correspondence to: Dr. Donald R. Miller,

Department of Anaesthesia, Ottawa General Hospital, 510

Smyth Road, Ottawa, Ontario K1H 8L6.

Phone: 613-737-8187. Fax: 613-737-8189.

Presented, in part, at the Annual Meeting of the Canadian Anaesthetists' Society, Edmonton, Alberta; June 1994.

Supported by a Research Grant from Hoffmann-La Roche, Canada.

*Present Address: Department d'anesthésie-réanimation,

Université de Montréal.

Accepted for publication 27th April, 1996. the $M-30$ and $M-45$ groups when compared with PLAC $(P<0.05)$, whereas propofol infusion requirements were similar among groups. Times to awakening and discharge from the Recovery Room and Day Care Unit, as well as TDT scores, were no greater in any midazolam group than in PLAC.

Conclusions: Midazolam 30-45 $\mu \mathrm{g} \cdot \mathrm{kg}^{-1}$ decreases the amount of propofol required for anaesthetic induction, without influencing recovery profiles or patient discharge times from the Day Care Unit. Despite careful modulation of the propofol infusion rate, six patients unexpectedly experienced intraoperative awareness with recall, with the lowest incidence occurring in those groups where patients had received midazolam.

Objectif: Évaluer l'influence du midazolam à doses croissantes sur la quantité de propofol requise en perfusion, et sur les caractéristiques et la qualité du réveil pendant une anesthésie intraveineuse totale au propofol/alfentany $/ \mathrm{O}_{2}$ (AIVT).

Méthodes: Quatre-vingt-dix sujets de classe ASA I et II devant subir une chirurgie arthroscopique du genou étaient répartis au hasard pour recevoir soit un placebo (Groupe PLAC), soit du midazolam à des doses de 15,30 ou $45 \mu \mathrm{g} \cdot \mathrm{kg}^{-1}$ (Groupes $M-15, M-30$ et $M-45)$. L'anesthésie était induite et entretenue au propofol (en perfusion initiale de $100 \mu \mathrm{g} \cdot \mathrm{kg}^{-1} \cdot \mathrm{min}^{-1}$ et ensuite réglée d'après la profondeur de l'anesthésie) et à l'alfentanil (dose de charge de $20 \mu \mathrm{g} \cdot \mathrm{kg}^{-1}$ suivie par une per. fusion de $0,5 \mu \mathrm{g} \cdot \mathrm{kg}^{-1} \cdot \mathrm{min}^{-1}$ ). En postopératoire, le temps du réveil, de la récupération et du congé était enregistré en plus d'une évaluation psychométrique au Trieger Dot Test (TDT).

Résultats: Six patient ayant éprouvé une reprise inattendue peropératoire de la conscience, l'étude a été arrêtée prématurément $(4 / 21=19,1 \%$ des patients avec PLAC vs $2 / 69=$ $2,9 \%$ des patients des groupes midazolam, $P<0,04)$. Pour l'induction, les besoins en propofol étaient inférieurs dans les groupe $M-30$ et $M-45$ comparativement au groupe PLAC $(P<$ $0,05)$, alors que les quantités de propofol requises en perfu. sion étaient identiques pour tous les groupes. La durée du réveil et du séjour en salle de réveil et à l'unité de chirurgie de jour n'était pas plus longue et les scores du TDT plus élevés dans les groupes midazolam que dans le groupe PLAC. Conclusion: Le midazolam 30-45 $\mu \mathrm{g} \cdot \mathrm{kg}^{-1}$ diminue la dose de propofol requise pour l'induction sans influencer le profil de 
la récupération et du congé de l'unité de jour. Malgré un modulation minutieuse de la vitesse de perfusion, six patients ont éprouvé une reprise de conscience inattendue avec rappel dont la plus basse incidence est survenue dans les groupes recevant du midazolam.

The technique of administering two or more hypnotic drugs to facilitate induction of general anaesthesia ("coinduction"), has gained considerable popularity. The rationale for this approach is the moderation of doserequirements, as well as side effects and costs, of the primary induction agent. Drug combinations which have demonstrated synergistic properties include thiopentone/midazolam, ${ }^{1,2}$ and propofol/midazolam. ${ }^{3-7}$

Despite the potential advantages of co-induction, reluctance to utilize midazolam or other benzodiazepines for outpatient anaesthesia persists, due to concerns regarding the potential for prolonged recovery. ${ }^{8}$ Although recent evidence suggests that propofol/midazolam co-induction does not delay hospital discharge times following very brief propofol anaesthesia, ${ }^{9}$. doseresponse relationships have not been clarified. Even less well understood are the effects of midazolam on propofol requirements associated with total intravenous anaesthesia (TIVA), and the influence of this drug combination on the quality of recovery from anaesthesia.

Due to these unresolved issues, a randomized, double-blind dose-finding study was undertaken to evaluate the effects of graded doses of midazolam on propofol induction requirements, and infusion rates necessary to provide total intravenous anaesthesia for relatively short out-patient procedures ( $<$ one hour in duration). A secondary aim was to evaluate the effects of low doses of midazolam on recovery times, as well as return of psychomotor function, and patient satisfaction, in the Day Care Surgery setting.

\section{Methods}

\section{Study population}

Ninety unpremedicated adult Day Care patients, who were scheduled to undergo either arthroscopic knee surgery or laparoscopic procedures, gave written informed consent to the protocol approved by the hospital Research Ethics Board. All subjects were between 18-65 yr of age, and ASA Physical Status Class I or II. Exclusion resulted for any of the following reasons: surgery scheduled to last $>1 \mathrm{hr}$; documented or possible allergy to midazolam or the other anaesthetic medications; age $<18$ or $>65 \mathrm{yr}$; pregnancy; history and/or physical findings of moderate or severe systemic disease involving the respiratory, cardiovascular or nervous sys- tems; hypertension (defined as preoperative $\mathrm{BP}>$ $160 / 90 \mathrm{mmHg}$ on at least two determinations); history of benzodiazepine, alcohol or chronic illicit drug use; or extremes of body habitus (defined as a bódy mass index either $<20$ or $>30 \mathrm{~kg} \cdot \mathrm{m}^{-2}$ ).

\section{Anaesthetic technique}

Consistent with established surgical day care procedures at the study institution, patients were unpremedicated. In the operating room, routine monitors were applied, and an 18 ga peripheral iv cannula was secured. Patients were then block-randomized (in five blocks of 20) into one of four study groups, according to a computer-generated randomization schedule, as follows:

Group PLAC: normal saline;

Group M-15: midazolam $15 \mu \mathrm{g} \cdot \mathrm{kg}^{-1}$;

G. up M-30: midazolam $30 \mu \mathrm{g} \cdot \mathrm{kg}^{-1}$;

Group M-45: midazolam $45 \mu \mathrm{g} \cdot \mathrm{kg}^{-1}$.

Blinding was established by preparing midazolam in coded syringes, on the morning of surgery, in concentrations of either $0.15,0.30$, or $0.45 \mathrm{mg} \cdot \mathrm{ml}^{-1}$ (for groups M-15, M-30 and M-45, respectively). This allowed for study drug/saline preparations to be delivered in a volume of $0.1 \mathrm{ml} \cdot \mathrm{kg}^{-1} i v$, in order to prevent group identification. Allocation concealment was achieved with the use of sealed envelopes.

While being pre-oxygenated, patients received a priming dose of atracurium, $0.03 \mathrm{mg} \cdot \mathrm{kg}^{-1} i \mathrm{v}$, followed by $0.1 \mathrm{ml} \cdot \mathrm{kg}^{-1} i v$ of study medication. One minute later, a loading dose of alfentanil, $20 \mu \mathrm{g} \cdot \mathrm{kg}^{-1}$ iv was infused. Induction of anaesthesia was achieved using propofol, by administering an initial bolus up to $1.0 \mathrm{mg} \cdot \mathrm{kg}^{-1} i v$, followed by $10 \mathrm{mg} i v$ increments at $5-10 \mathrm{sec}$ intervals, until the eyelid reflex was abolished, and there was no further response to verbal command. Paralysis was achieved with atracurium $0.47 \mathrm{mg} \cdot \mathrm{kg}^{-1}$, and the trachea was intubated using direct laryngoscopy four minutes after administration of the study drug. Mechanical ventilation was established using an air/oxygen mixture in a 2:1 ratio, and minute ventilation was adjusted to maintain a PETCO $\mathrm{P}_{2}$ between $30-35 \mathrm{mmHg}$.

Anaesthesia was maintained with an infusion of propofol, beginning at $100 \mu \mathrm{g} \cdot \mathrm{kg}^{-1} \cdot \mathrm{min}^{-1}$, and titrated at rates between $80-200 \mu \mathrm{g} \cdot \mathrm{kg}^{-1} \cdot \mathrm{min}^{-1}$, according to both patient and surgical requirements. Each step increase in the infusion rate of propofol was preceded by an additional bolus dose of propofol $300 \mu \mathrm{g} \cdot \mathrm{kg}^{-1}$. Rate adjustments were made in order to maintain heart rate (HR) and systolic blood pressure (SBP) within $\pm 20 \%$ of the patient's baseline (preoperative) values, or in response to any movement. Prior to skin incision, a second bolus of alfentanil $15 \mu \mathrm{g} \cdot \mathrm{kg}^{-1} i v$ was administered, followed by a constant infusion set at 0.5 
$\mu \mathrm{g} \cdot \mathrm{kg}^{-1} \cdot \mathrm{min}^{-1}$. Additional muscle relaxation was achieved with iv boluses of atracurium, in order to maintain 1-2 twitches on the train-of-four response, applied to the ulnar nerve. Throughout surgery, nitrous oxide and potent inhalational anaesthetic agents were strictly avoided (total intravenous anaesthesia).

Within $15 \mathrm{~min}$ of the anticipated completion of surgery, alfentanil was discontinued, while the infusion of propofol was maintained until approximately 3-5 min before skin closure. Neostigmine $50 \mu \mathrm{g} \cdot \mathrm{kg}^{-1} i v$ and atropine $20 \mu \mathrm{g} \cdot \mathrm{kg}^{-1} i v$ were administered to reverse neuromuscular block, and the patients were extubated when awake, and then immediately transferred to the Post Anaesthesia Care Unit. Postoperative analgesia was provided with fentanyl 25-50 $\mu \mathrm{g} i v \mathrm{prn}$, and dimenhydrinate $25 \mathrm{mg}$ iv was administered for nausea and/or vomiting as required.

\section{Measurements}

Intraoperatively, the effects of the midazolam-propofol combination were evaluated by comparing the amount of propofol required to induce anaesthesia (loss of response to verbal command, and abolition of the eyelid reflex), and by comparing the infusion rates of propofol at five min intervals during maintenance of anaesthesia. Heart rate (HR) and systolic blood pressure (SBP) were measured non-invasively with a Dinamap 1846 SX cardiac monitor, and recorded at baseline (BL), one minute after induction (IND), one minute after tracheal intubation (INT), and every $10 \mathrm{~min}$ thereafter throughout surgery.

Postoperatively, a blinded, trained recovery room nurse remained in constant attendance with the patient. She recorded the following data: time to awakening (defined as the time to spontaneous eye opening); time to obey verbal command; Observer's Assessment of Alertness/Sedation Scale (OAASS); ${ }^{10}$ and the Trieger Dot Test. " Each evaluation was conducted at the following times: preoperatively (baseline - BL), and then at 30,60 and $120 \mathrm{~min}$ after discontinuation of the propofol infusion. The actual time of hospital discharge was documented, and $24-48 \mathrm{hr}$ postoperatively, all patients responded to a questionnaire by telephone interview, to evaluate their subjective impressions of the anaesthetic. The possibility of explicit recall of intraoperative events was assessed by asking patients to describe the last thing they remembered before going to sleep, the first item they recalled upon awakening after the operation, and whether or not they recalled any event in between. Finally, patients were also asked to rate their overall degree of satisfaction with the anaesthetic on a threepoint scale as being either pleasant, tolerable, or intolerable.
TABLE I Patient characteristics

\begin{tabular}{lclll}
\hline Characteristic & $\begin{array}{l}P L A C \\
(n=2 I)\end{array}$ & $\begin{array}{l}M-15 \\
(n=24)\end{array}$ & $\begin{array}{l}M-30 \\
(n=23)\end{array}$ & $\begin{array}{l}M-45 \\
(n=22)\end{array}$ \\
\hline Age (yr) & $34 \pm 11$ & $35 \pm 9$ & $34 \pm 8$ & $38 \pm 12$ \\
Sex (m/f) & $5 / 16$ & $7 / 17$ & $10 / 13$ & $6 / 16$ \\
Weight (kg) & $68 \pm 12$ & $67 \pm 11$ & $69 \pm 11$ & $69 \pm 12$ \\
ASA (I/I) & $21 / 0$ & $22 / 2$ & $23 / 0$ & $22 / 0$ \\
Procedure & $8 / 6 / 7$ & $13 / 7 / 4$ & $9 / 6 / 8$ & $13 / 7 / 2$ \\
Lap/Arth/Other $(n)$ & & & & \\
\hline
\end{tabular}

Lap $=$ laparoscopy $;$ Arth $=$ arthroscopy .

\section{Statistical analysis}

Demographic data were analysed using the Student's $t$ test and Chi-square statistic. Between-groups comparison of propofol induction requirements was also performed by the Student's $t$ test, and inter-group comparisons of propofol infusion rates, as well as haemodynamic variables (HR, SBP) were conducted using repeated-measures analysis of variance (ANOVA). The OAASS and Trieger Dot Scores were assessed by the Kruskal-Wallis test at each time period, and the incidence of awareness with recall was analysed using Fisher's Exact Test. Data are presented as mean \pm SD throughout the text, figures and tables. Statistical significance was assumed when $P<0.05$.

\section{Results}

The study was terminated prematurely due to an unexpectedly high incidence of intraoperative awareness with recall. However, recruitment of the majority of subjects $(90 / 100)$, and the process of block randomization, permitted analysis of anaesthetic requirements, in addition to recovery data. Demographic characteristics, including age, body weight, and ASA classification, were similar amongst the four groups (Table I). Although there were more women than men in this study, the proportion of females to males was not different among groups.

\section{Cases of awareness with recall}

Unexpectedly, six patients (6.7\%) experienced awareness with recall during the course of their anaesthetic. Four of these six patients were in the PLAC group, whereas one patient experienced awareness with recall in each of the M-15 and M-45 groups, respectively. The overall incidence of intraoperative awareness was therefore lower following midazolam co-induction $(2 / 69=$ $2.9 \%$ of patients in Groups M-15, M-30, M-45), compared with a $17 \%$ incidence of awareness in the PLAC group $(P=0.038)$. Heart rate, SBP, and mean rates of propofol infusion were numerically greater in the six 


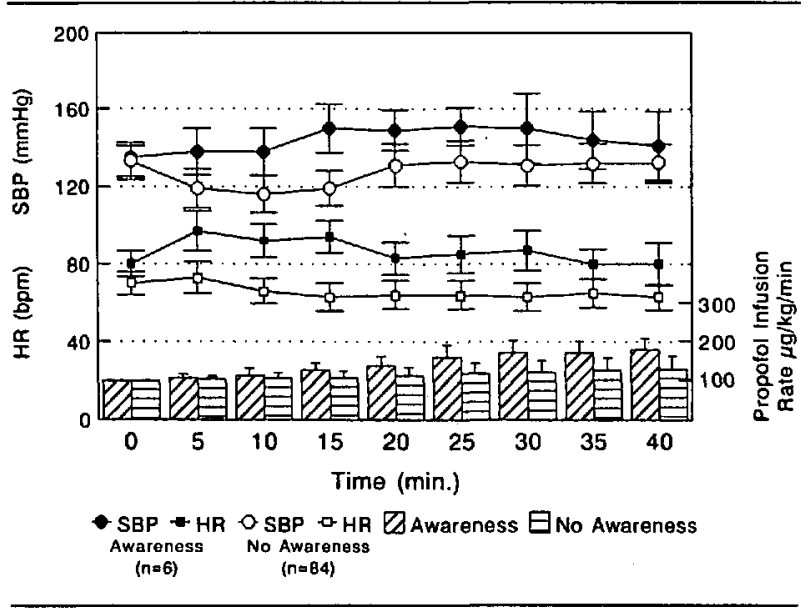

FIGURE 1 Systolic blood pressure (SBP) and heart rate (HR) (mean \pm SD) of those patients who experienced awareness with recall (solid symbols), and the remainder who did not (hollow symbols). In the lower portion of the panel, average propofol infusion rates were numerically greater in patients who experienced awareness. These data were not subject to statistical analysis, as there was a large proportional difference in the number of patients who experienced awareness vs those who did not.

patients who experienced intraoperative awareness, compared with those who did not (Figure 1). However, statistical analysis was not applied to these data, in view of the uneven distribution of patient numbers. Although five of the six patients experienced mild or moderate pain with their recall, none of the patients described any psychological stress or anxiety. Furthermore, despite their experience of awareness, three of the six patients rated the quality of the study anaesthetic to have been superior to their last. Other aspects of the recall experiences are outlined in Table II.

\section{Propofol requirements for induction and maintenance of anaesthesia}

The amount of propofol required to induce anaesthesia in the PLAC group was $1.7 \pm 0.4 \mathrm{mg} \cdot \mathrm{kg}^{-1}$. Although the induction dose was similar in the M-15 group (1.5 $\pm 0.5 \mathrm{mg} \cdot \mathrm{kg}^{-1}$ ), both the intermediate and higher doses of midazolam (groups M-30 and M-45) were associated with an approximate $25 \%$ decrease in the amount of propofol necessary for anaesthetic induction (1.3 \pm 0.4 $\mathrm{mg} \cdot \mathrm{kg}^{-1}, P<0.05$ in both groups compared with PLAC). Throughout the course of surgery, increased propofol infusion rates were observed in every group, as required to maintain haemodynamic indices within $\pm 20 \%$ of preoperative values. However, there were no differences in average infusion requirements between groups at corresponding times during the intraoperative period ( $P=$ NS, Figure 2). As many of the anaesthetics were complete after $35 \mathrm{~min}$, propofol infusion rates were not compared past this time period.

\section{Haemodynamic response}

Overall, the TIVA anaesthetic technique was associated with a stable cardiovascular response. Heart rate increased after tracheal intubation, but similar HR values were observed throughout the study period in all groups (mean values 60-82 bpm, Figure 3). A modest decrease in SBP characterized the haemodynamic response during induction of anaesthesia (Figure 4), but neither fluid boluses nor vasopressors was required in any patient. However, only with the highest dose of midazolam (Group M-45), was an increase in blood pressure prevented in response to the stress of tracheal intubation $(P<0.02)$. Apart from such transient differences, mean SBP values remained similar at corresponding times throughout the propofol infusion.

\section{Recovery characteristics}

This anaesthetic technique was associated with prompt recovery, as reflected by the fact that mean times to awakening were less than six minutes following discontinuation of the propofol infusion in every group (Table III). During early recovery, the Observer's Assessment of Alertness and Sedation scores were similar at corresponding periods, compared with respective preoperative values (Table III). Although the Trieger Dot Test demonstrated altered performance at $\mathrm{t}=30 \mathrm{~min}$, there were no differences among groups regarding the number of dots missed at any postoperative measurement period (Figure 5). Of clinical relevance, the times to discharge from the Post Anaesthesia Care Unit, as well as the Day Care Unit, were no greater in any midazolam group than in the PLAC group (Table III).

\section{Discussion}

This study demonstrates that, in unpremedicated patients, the dose of midazolam required to reduce the amount of propofol necessary for induction of general anaesthesia, is between $30-45 \mu \mathrm{g} \cdot \mathrm{kg}^{-1}$. However, in this dosage range, midazolam does not modify the amount of propofol required for maintenance of anaesthesia, in relatively brief $(<1 \mathrm{hr})$ outpatient procedures. Of additional clinical relevance, these data establish that preinduction boluses of midazolam (approximately 1.5-3 mg $i v$ for an average $70 \mathrm{~kg}$ patient), are not associated with prolongation of either recovery or discharge times from the Day Care Unit. The one unexpected finding was the observation that six patients (6.7\%) experienced awareness with recall during the course of their anaesthetic. 
TABLE II Awareness with recall - patient experiences

\begin{tabular}{|c|c|c|c|c|c|c|}
\hline Group & $P L A C^{*}$ & $P L A C^{*}$ & $P L A C^{*}$ & $P L A C^{*}$ & $M-15$ & $M-45$ \\
\hline Age & 33 & 21 & 29 & 38 & 32 & 29 \\
\hline Gender & $\mathrm{F}$ & $\mathrm{F}$ & $\mathbf{F}$ & $\mathbf{F}$ & $\mathrm{F}$ & $\mathbf{F}$ \\
\hline Surgery & LAP & ARTH & ARTH & LAP & LAP & LAP \\
\hline Movement & Yes & Yes & No & Yes & Yes & Yes \\
\hline Auditory & None & "Stapling" & None & None & "Voices" & None \\
\hline Pain & $2-3$ & 2 & 2 & 1 & 0 & 2 \\
\hline Satisfaction & 2 & 1 & 2 & 2 & 1 & 2 \\
\hline Comments & $\begin{array}{l}\text { "Very good com- } \\
\text { pared with } 1987 \\
\text { anaesthetic" }\end{array}$ & $\begin{array}{l}\text { "Request same } \\
\text { anaesthetic } \\
\text { again" }\end{array}$ & $\begin{array}{l}\text { "Felt my knee } \\
\text { being moved" }\end{array}$ & $\begin{array}{l}\text { "Experience was } \\
\text { not unpleasant" }\end{array}$ & $\begin{array}{l}\text { "Request same } \\
\text { anaesthetic } \\
\text { again" }\end{array}$ & $\begin{array}{l}\text { "It decreased my } \\
\text { anxiety for next } \\
\text { time" }\end{array}$ \\
\hline
\end{tabular}

$* P<0.05$, incidence of awareness with recall in PLAC group, compared with MID groups combined.

LAP = Laparoscopy; ARTH = arthroscopy; Pain: $0=$ none; $1=$ mild $2=$ moderate $; 3=$ severe. Satisfaction: $1=$ pleasant; $2=$ tolerable; $3=$ unpleasant.

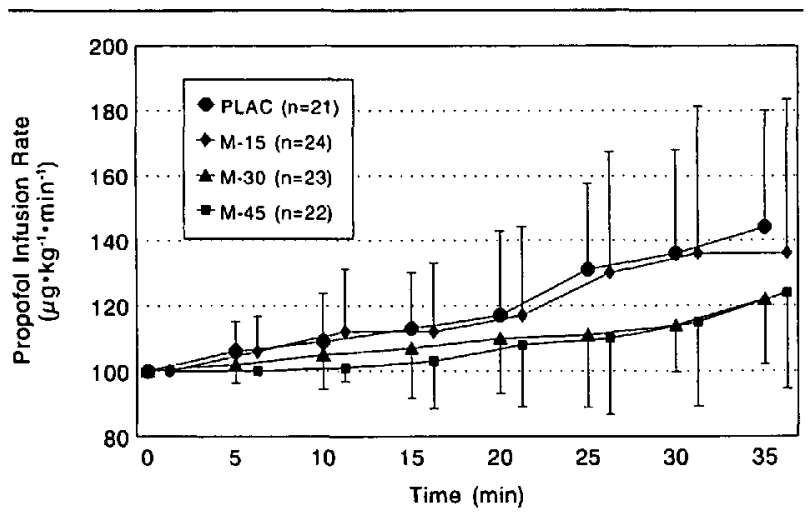

FIGURE 2 Propofol infusion rates (mean \pm SD) following induction of anaesthesia $(t=0)$, and every 5 min thereafter, for the next $35 \mathrm{~min}$. PLAC = placebo; $\mathrm{M}-15=$ midazolam $15 \mu \mathrm{g} \cdot \mathrm{kg}^{-1}, \mathrm{M}-30=$ midazolam $30 \mu \mathrm{g} \cdot \mathrm{kg}^{-1}, \mathrm{M}-45=$ midazolam $45 \mu \mathrm{g} \cdot \mathrm{kg}^{-1}$.

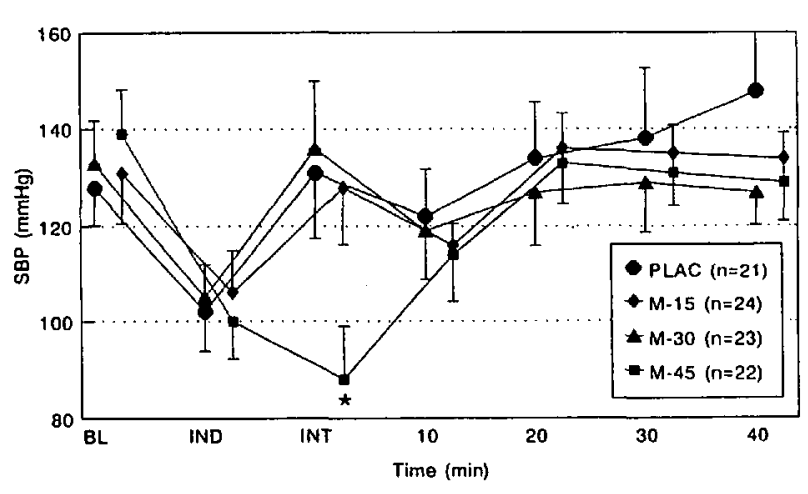

$\cdot p<0.02$. Diflerent from PLAC, $M-15, M-30$

FIGURE 4 Systolic blood pressure at baseline, one minute after induction of anaesthesia, one minute after tracheal intubation, and every $10 \mathrm{~min}$ thereafter for the next $40 \mathrm{~min}$. For abbreviations, refer to legends of Figures 1 and 2.

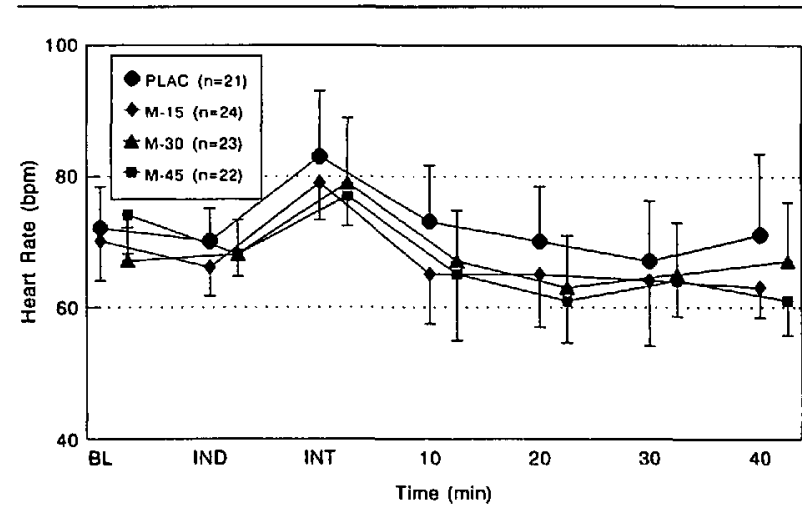

FIGURE 3 Heart rate (mean \pm SD) at baseline (BL), one min after induction of anaesthesia (IND), one minute after tracheal intubation (INT), and every $10 \mathrm{~min}$ thereafter for the next $40 \mathrm{~min}$. For remainder of abbreviations refer to legend of Figure 2.

TABLE III Influence of midazolam on recovery

\begin{tabular}{lcccc}
\hline & $\begin{array}{l}\text { PLAC } \\
(n=2 l)\end{array}$ & $\begin{array}{l}M-15 \\
(n=24)\end{array}$ & $\begin{array}{l}M-30 \\
(n=23)\end{array}$ & $\begin{array}{l}M-45 \\
(n=22)\end{array}$ \\
\hline Group & $37 \pm 9$ & $37 \pm 12$ & $40 \pm 14$ & $41 \pm 15$ \\
Duration of infusion (min) & $37 \pm 2.8$ & $4.4 \pm 2.0$ & $5.7 \pm 3.4$ & $5.7 \pm 3.4$ \\
Awakening time (min) & $5.1 \pm 2.4$ & & & \\
OAASS & & & & \\
- 30 min & $4.1 \pm 0.4$ & $4.4 \pm 0.5$ & $4.0 \pm 0.9$ & $4.4 \pm 0.5$ \\
- 60 min & $4.0 \pm 0.4$ & $4.3 \pm 0.5$ & $3.8 \pm 0.9$ & $4.4 \pm 0.5$ \\
Discharge PAR (min) & $57 \pm 22$ & $60 \pm 18$ & $60 \pm 23$ & $64 \pm 16$ \\
Discharge DCU (min) & $152 \pm 88$ & $165 \pm 30$ & $170 \pm 64$ & $159 \pm 44$ \\
\hline
\end{tabular}

OAASS = Observer's assessment of alertness/sedation scale; PAR = Post-anesthesia recovery room; DCU = Day care unit.

Midazolam and awareness with recall

Although intraoperative awareness is a well-described entity which occurs with relatively low frequency (the incidence of spontaneous recall is approximately 0.1 - 


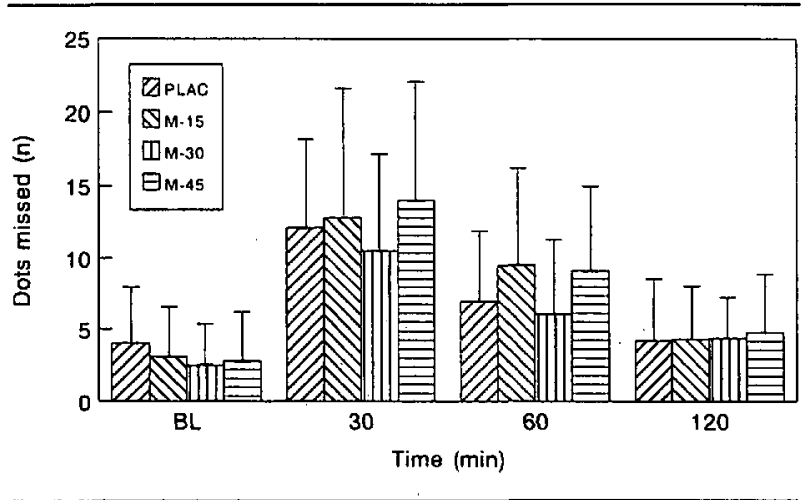

FIGURE 5 Trieger det scores (mean $\pm \mathrm{SD}$ ) at baseline (preoperatively), and 30,60 and $120 \mathrm{~min}$ following emergence from anaesthesia. The number of dots missed was greatest at $t=30 \mathrm{~min}$ in all groups, but there were no differences occurring among groups at corresponding times. For abbreviations, refer to legend of Figure 2.

$0.2 \%$ of all general anaesthetics),,$^{12}$ the problem is of great clinical relevance due to the potential for devastating post-operative sequelae. These include a constellation of symptoms ranging from fear of hospitals and distrust of medical personnel, to the syndrome of posttraumatic stress disorder, with symptoms of sleep disturbances, dreams, flashbacks, and anxiety which may last for years. ${ }^{13}$

In the current study, six cases of awareness with recall occurred (overall incidence of $6.7 \%$ ). The unexpected frequency of these unusual occurrences prompted the investigators to notify the institutional Research Ethics Board, in addition to seeking the advice of an independent external reviewer, after five patients had experienced awareness. During the review process, it was suggested that the first five cases of recall were probably the result of inadequate anaesthesia. However, as uncoding revealed that four of these patients had received placebo, and the fifth patient had the lowest dose of midazolam (Group M-15), it was considered justifiable to allow the study to continue, but with the placebo arm dropped. When the 90th patient in the study experienced recall (Group M-45), the study was terminated for ethical reasons.

To explain these findings, it must be emphasized that the study was designed with infusion rates of propofol and alfentanil which were set only initially at the lower end of recommended levels for TIVA (100 $\mu \mathrm{g} \cdot \mathrm{kg}^{-1} \cdot \mathrm{min}^{-1}$ and $0.5 \mu \mathrm{g} \cdot \mathrm{kg}^{-1} \cdot \mathrm{min}^{-1}$, respectively), in order to evaluate the influence of midazolam on infusion requirements of propofol during total intravenous anaesthesia. Whenever patients demonstrated signs of inadequate anaesthesia, supplemental propofol boluses, and step increases in the infusion rate were administered immediately. To minimize variability, only two individuals (DRM and RJM) were involved in the administration of the anaesthetics. Despite careful intraoperative observation, and what were thought to have been appropriate adjustments in the propofol regimen, six patients experienced recall. These findings emphasize that it is impossible to ensure that patients are unaware during anaesthesia, particularly when using less common techniques such as total intravenous anaesthesia in paralysed patients. In this regard, it would appear reasonable to consider the use of benzodiazepines as an additional component of a TIVA regimen, when administering propofol/opioid total intravenous anaesthesia. Furthermore, high initial infusion rates of propofol should be administered $\left(120-180 \mu \mathrm{g} \cdot \mathrm{kg}^{-1} \cdot \mathrm{min}^{-1}\right.$ for the first 10 $\mathrm{min}$ ), and not decreased below $100-140 \mu \mathrm{g} \cdot \mathrm{kg}^{-1} \cdot \mathrm{min}^{-1}$ during the next two hours. ${ }^{14}$ Alternatively, nitrous oxide can easily be introduced as part of this anaesthetic which, although no longer a TIVA technique per se, may also allow for reduced propofol requirements. ${ }^{14}$

In reviewing the individual cases of awareness with recall, several other issues are noteworthy. First, the patients were all young women (21-38 yr). Five of the six moved at some point during the course of their anaesthetic, and these patients collectively had higher heart rates and blood pressures intraoperatively, compared with the majority of patients who did not experience recall. Five of the six patients described pain of either mild or moderate intensity. Despite these findings, during the postoperative interview, each patient described her overall anaesthetic experience as having been either pleasant or tolerable. Furthermore, half the patients stated that they would request the same anaesthetic again for future surgery. Thus, the experiences of intraoperative awareness in this study did not appear to result in any signs or symptoms of a post-traumatic stress disorder, or other negative sequelae.

Several factors could explain the generally favourable experience of the individuals who had awareness with recall. First, propofol is known to produce a pleasant, and occasionally euphoric recovery, with a low incidence of postoperative nausea and vomiting. ${ }^{14}$ Therefore, all patients in the study would have benefited from this aspect of the anaesthetic regimen. Secondly, the infusion scheme for alfentanil, although incorporating a relatively low rate, appeared to produce sufficient analgesia for these short procedures, so that no patient experienced pain of any great duration or severity. Thirdly, all subjects benefited, as a result of their participation in the study, from the care of a highly-trained recovery room nurse (KAH), who remained in attendance with each patient until the time of discharge from hospital. 


\section{Midazolam/propofol co-induction}

The pharmacological basis of co-induction has been shown to result from synergistic, rather than simply additive effects of various drug combinations. This concept has been evaluated using the method of isobolographic analysis. ${ }^{15,16}$ Synergy between midazolam and propofol has been shown to exist in several previous studies, in which a $20-55 \%$ decrease in the amount of propofol required for induction of anaesthesia has been demonstrated, with midazolam doses ranging from $20-70 \mu \mathrm{g} \cdot \mathrm{kg}^{-1} .6,8,9$ While we were unable to detect an influence of midazolam on propofol requirements at a dose below $30 \mu \mathrm{g} \cdot \mathrm{kg}^{-1}$, subtle differences in study populations, as well as differences in the timing of administration of anaesthetic medications, can readily account for these variations in dose-response relationships.

One additional factor which may explain the quantitative differences between these studies is the amount of opioid analgesic which was administered. Vuyk et al. recently evaluated the pharmacodynamic interaction of alfentanil and propofol for lower abdominal surgery, and demonstrated that, by increasing the plasma concentration of alfentanil from 50 to $150 \mathrm{ng} \cdot \mathrm{ml}^{-1}$, the effective concentration $\left(\mathrm{EC}_{50}\right)$ of propofol for the regaining of consciousness decreased from 3.8 to $0.8 \mu \mathrm{g} \cdot \mathrm{ml}^{-1}{ }^{17}$ Although the pharmacodynamic interaction between propofol and alfentanil was found to be nonlinear, the different amounts of opioid used in the above studies would have had an important influence on propofol requirements, in addition to the effects of midazolam. It is important to appreciate that, in our study, although the loading dose and infusion scheme of alfentanil was not computer-driven to achieve a specific target concentration, the infusion regimen was carefully standardized in an attempt to minimize the effects of varying opioid concentrations as a potential confounding variable. Future investigations should focus on the application of the interaction models developed by Vuyk et al.,$^{17}$ when all three drugs are used in combination to provide general anaesthesia. As suggested by Stanski and Shafer, in this way, dosing guidelines can be developed which are nearly optimal, in the sense that they will provide for the most rapid recovery when the duration of anaesthesia and surgery are not known a priori. ${ }^{18}$

\section{Effects of midazolam on maintenance of anaesthesia and recovery}

Despite the moderating effects of midazolam on induction doses of propofol, infusion requirements of this drug were similar in both treatment and control groups. From an initial setting of $100 \mu \mathrm{g} \cdot \mathrm{kg}^{-1} \cdot \mathrm{min}^{-1}$, a gradual, $10-30 \%$ increase in the rate of propofol administration was required in every group, in order to maintain car- diovascular signs of adequate anaesthesia. One possible explanation for the observed between-groups similarity of propofol infusion requirements is related to both the dose and timing of midazolam administration. As midazolam was administered in relatively small boluses prior to induction of anaesthesia, it would be anticipated that midazolam effect-site concentration would have peaked shortly following tracheal intubation, and would have declined steadily thereafter. Although plasma drug concentrations were not measured in this study, it is wellestablished that the initial decline of the plasma-decay curve of a drug whose pharmacokinetic behaviour is best described by a multicompartment model, is primarily the result of redistribution. ${ }^{19}$ It would, therefore, have been anticipated that small pre-induction boluses of this relatively short-acting benzodiazepine would have exerted little or no influence on the maintenance requirements of propofol, unless supplemental doses, or a continuous low-dose infusion of midazolam had been administered concurrently. Application of these same concepts also provides the most likely explanation for the fact that anaesthetic supplementation with midazolam did not prolong either recovery or discharge times following this general anaesthetic technique.

\section{Summary}

In conclusion, $30 \mu \mathrm{g} \cdot \mathrm{kg}^{-1}$ was found to be the lowest dose of midazolam to reduce the amount of propofol required for induction of general anaesthesia. However, when administered prior to induction, midazolam, up to a dose of $45 \mu \mathrm{g} \cdot \mathrm{kg}^{-1}$, does not decrease the amount of propofol required for maintenance of anaesthesia for relatively brief $(<1 \mathrm{hr})$ outpatient procedures. Of greater importance, midazolam doses which correspond to $1.5-3 \mathrm{mg}$ for an average $70 \mathrm{~kg}$ patient, were found to have no clinically important effects on recovery profiles or discharge times from the Day Care Unit. Finally, despite careful modulation of the propofol infusion rate, six patients unexpectedly experienced intraoperative awareness with recall, with the lowest incidence occurring in those groups where patients had received midazolam

\section{Acknowledgments}

We extend our deepest appreciation to the anaesthetists, nurses, and surgeons of the Ottawa General Hospital, whose patience and co-operation made this study possible. We also offer a special thanks to Mr. Denis Boisvert for his expertise in conducting the statistical analysis.

\section{References}

1 Vinik HR, Bradley EL Jr, Kissin I. Midazolam for coin- 
duction of thiopental anesthesia in patients. Anesthesiology 1990; 73: A1216.

2 Tverskoy M, Fleyshman G, Bradley EL Jr, Kissin I. Midazolam-thiopental anesthetic interaction in patients. Anesth Analg 1988; 67: 342-5.

3 Short TG, Chui PT. Propofol and midazolam act synergistically in combination. Br J Anaesth 1991; 67: 539-45.

4 McClune S, McKay AC, Wright PMC, Patterson CC, Clarke RSJ. Synergistic interaction between midazolam and propofol. Br J Anaesth 1992; 69: 240-5.

5 Caba F, Echevarria M, Moráles $R$, Guerréro JA, Rodriguez $R$. The synergism of midazolam and propofol in the induction of anesthesia. (Spanish) Rev Esp Anestesiol Reanim 1993; 40: 69-71.

6 Vinik HR, Bradley EL Jr, Kissin I. Propofol-midazolamalfentanil combination: is hypnotic synergism present? Anesth Analg 1993; 76: S450.

7 Short TG, Plummer JL, Chui PT. Hypnotic and anaesthetic interactions between midazolam, propofol, and alfentanil. Br J Anaesth 1992; 69: 162-7.

8 DeLucia JA, White PF. Effect of midazolam on induction and recovery characteristics of propofol. Anesth Analg 1992; 74: S63.

9 Elwood T, Huchcroft S, MacAdams C. Midazolam coinduction does not delay discharge after very brief propofol anaesthesia. Can J Anaesth 1995; 42: 114-8.

10 Chernik DA, Gillings $D$, Laine $H$, et al. Validity and reliability of the observer's assessment of alertness/sedation scale: study with intravenous midazolam. J Clin Psychopharmacol 1990; 10: 244-51.

11 Newman MG, Trieger N, Miller JC. Measuring recovery from anesthesia - a simple test. Anesth Analg 1969; 48: 136-40.

12 Liu WHD, Thorp TAS, Graham SG, Aitkenhead AR. Incidence of awareness with recall during general anaesthesia. Anaesthesia 1991; 46: 435-7.

13 Moerman N, Bonke B, Oosting J. Awareness and recall during general anesthesia. Anesthesiology 1993; 79: 454-64.

14 Smith I, White PF, Nathanson M, Gouldson R. Propofol. An update on its clinical use. Anesthesiology 1994; 81: 1005-43.

15 Berenbaum MC. What is synergy? Pharmacol Rev 1989; 41: 93-141.

16 Kissin I, Vinik HR, Castillo R, Bradley EL Jr. Alfentanil potentiates midazolam-induced unconsciousness in subanalgesic doses. Anesth Analg 1990; 71: 65-9.

17 Vuyk J, Lim T, Engbers FHM, Burm AGL, Vletter AA, Bovill JG. The pharmacodynamic interaction of propofol and alfentanil during lower abdominal surgery in women. Anesthesiology 1995; 83: 8-22.

18 Stanski DR, Shafer $S L$. Quantifying anesthetic drug inter- action. Implications for drug dosing (Editorial). Anesthesiology 1995; 83: 1-5.

19 Hughes MA, Glass PSA, Jacobs JR. Context-sensitive half-time in multicompartment pharmocokinetic models for intravenous anesthetic drugs. Anesthesiology 1992; 76 : $334-41$. 